\title{
EFEKTIVITAS PEMBELAJARAN AKTIF, KREATIF, EFEKTIF DAN MENYENANGKAN (PAKEM) PADA MATERI MATRIKS
}

\author{
ENDANG WIJAYANTI
}

SMA Negeri 1 Comal, Jawa Tengah, Indonesia

Email : endangwijayanti894@gmail.com

\begin{abstract}
ABSTRAK
Penelitian berbasis eksperimen yang dilaksanakan memiliki beberapa tujuan diantaranya : (1) Melihat adanya korelasi antara hasil belajar/prestasi siswa yang pada proses pembelajaranya menggunakan Metode Pembelajaran Aktif, Kreatif, Efektif dan Menyenangkan PAKEM dan tanpa menggunakan PAKEM pada mata pelajaran Materi matriks, (2) Mengetahui efektifitas penggunaan PAKEM terhadap hasil belajar/prestasi siswa. Pada penelitian memiliki Populasi Siswa SMA Negeri 1 Comal Tahun Pelajaran 2021/2022. Sampel yang digunakan pada penelitian diambil secara acak. Dan Sampel pada penelitian ini adalah siswa ada 2 kelas dan satu kelas eksperimen. Proses awal penelitian ini memiliki rangkaian uji awal yang merupakan uji coba reliabilitas, validitas, tingkat kesukaran, dan daya pembeda soal. Setelah diadakan treatment terhadap dua kelas/kelompok dengan perlakuan berbeda maka dilakukan uji statistik. Dari hasil pengujian data penelitian memperlihatkan adanya perbedaan pada tingkat prestasi yang melalui proses pembelajaran menggunakan PAKEM dan tanpa menggunakan PAKEM. Dan diperoleh hasil tes pada kelompok eksperimen sebesar 76,84 dan hasil tes kelompok kelas control sebesar 61,75 kemudian setelah dilakukan perhitungan statistik diperoleh $t_{\text {hitung }}=$ 6,22 sedangkan $t_{\text {tabel }}=2,68$ dari hasil yang diperoleh maka dapat disimpulkan bahwa pada penelitian ini bahwa siswa yang melalui proses pembelajaran menggunakan PAKEM PAKEM memperoleh kemampuan/hasil prestasi yang lebih baik daripada siswa melalui proses pemebelajaran tanpa PAKEM.
\end{abstract}

Kata kunci: Efektivitas, Matriks, PAKEM

\section{ABSTRACT}

The experimental-based research carried out has several objectives including: (1) Seeing the correlation between learning outcomes/achievements of students who in the learning process use the Active, Creative, Effective and Fun PAKEM Learning Method and without using PAKEM on matrix material subjects, (2) Knowing the effectiveness of using PAKEM on student learning outcomes/achievements. In this study, the population of SMA Negeri 1 Comal is the student population for the 2021/2022 academic year. The sample used in the study was taken randomly. And the sample in this study were students there were 2 classes and one experimental class. The initial process of this research has a series of initial tests which are tests of reliability, validity, level of difficulty, and discriminating power of questions. After the treatment of two classes/groups with different treatments was carried out, statistical tests were carried out. From the results of testing the research data, it shows that there are differences in the level of achievement through the learning process using PAKEM and without using PAKEM. And obtained the test results in the experimental group of 76.84 and the test results of the control class group of 61.75 then after statistical calculations obtained t_count $=6.22$ while t_table $=2.68$ from the results obtained it can be concluded that in this study that students who go through the learning process using PAKEM get better abilities/achievements than students who go through the learning process without PAKEM.

Keywords: Effectiveness, Matrix, PAKEM

\section{PENDAHULUAN}

Pada Dunia Pendidikan saat ini, seperti kita ketahui bersama khususnya pada saat pandemi, proses pembelajaran selain menggunakan metode secara online dan canggih namun harus tetap menyenangkan, dan esensi menyenangkan ini merupakan metode yang harus dilakukan inovasi, 
seperti pada penelitian yang dilaksanakan pada siswa SMA Negeri 1 Comal pada proses pembelajarannya menggunakan konsep definisi dari Pendidikan nasional dan metode pembelajaran yang menyenangkan. Tujuan Pendidikan memiliki esensi membentuk manusia yang berbudi luhur, berdisiplin, bekerja keras, yang yang lebih utama Bertaqwa kepada Tuhan Yang Maha Esa (Mustafa, n.d.; Nym et al., 2019; Qurohman et al., 2019).

Dalam kegiatan belajar mengajar, sering sekali mengalami kejenuhan sehingga pada proses pembelajaran pada siswa harus ada inovasi, kemudian sarana dan pra sarana yang dimiliki perguruan tinggi guna menunjang proses belajar juga harus memadai sehingga berkolerasi positif terhadap keberhasilan pembelajaran (Rohim \& Zahri, 2018). Hal terpenting selanjutnya ada penggunaan metode dan konsep pembelajaran yang tepat akan tertanam Guru menggunakan metode yang inovatif dan menyenangkan, serta mudah diterima oleh siswa (Lestari, 2014). Keunggulan metode PAKEM diantaranya yaitu pengelolaan difddddkelas akan menjadi lebih hidup dan semarak sehingga akan mengurangi kejenuhan siswa sehingga akan menambah semangat dan minat untuk belajar dan berprestasi. Dan kemudian dari hasil observasi dan wawancara di peroleh informasi bahwa nilai mata pelajaran Materi Matriks belum maksimal. Sehubungan dengan beberapa latar belakang tersebut, dilakukan Penelitian ini dengan membuat inovasi pembelajaran yang Aktif, Kreatif, efektif dan menyenangkan dalam proses pengajaran mata pelajaran Materi matriks.

Pada Penelitian yang dilakukan oleh Sutiasih (2019) menjelaskan bahwa penggunaan bantuan alat Android Valid dan Praktis, kemudian penelitian berikutnya dilakukan oleh Sujadi(2017) dimana penelitian ini menunjukkan bahwa pembelajaran dengan menyenangkan dapat mengurangi kesalahan jaringan pada perngakat. Serta penelitian yang dilakukan oleh Nur Aini (2020) memberikan kesimpulan bahwa Pembelajaran memberikan pengaruh pada lingkungan dengan metode pembelajaran yang baik. Selajutnya Mustika (2015) menyimpulkan bahwa prioritas pembangunan yang sudah terbangun memiliki prioritas dan implementasi dengan system yang terpadu.

Kemudian melihat definisi efektifitas pada penelitian ini merupakan adanya pengaruh yang baik terhadap prestasi siswa (Baharun et al., 2019). Pada penelitian yang dilakukan mengambil data mata pelajaran dengan nama Materi matriks, dimana mata pelajaran tersebut mencangkup/memiliki scope suatu konsep yang memuat tentang perencanaan dan struktur pengoperasian dasar komputer, dimana pada mata pelajaran ini merancang komponen hardware secar efektif dan multiguna dalam berbagai kebutuhan (Awan et al., 2020; Purnama, 2012; Sungkar et al., 2019).

PAKEM (Pembelajaran yang Aktif, Kreatif, Efektif dan Menyenangkan) merupakan metode pembelajaran dalam upaya peningkatan hasil prestasi belajar siswa dengan pembelajaran yang menyenangkan (Nym et al., 2019; Sekolah, 2009). Materi yang akan dijadikan bahan penelitian adalah mata pelajaran Materi matriks. Jadi penelitian ini merupakan suatu penelitian yang memiliki tujuan memperoleh informasi mengetahui korelasi antara penggunaan inovasi pembelajaran Pembelajaran yang Aktif, Kreatif, Efektif dan Menyenangkan dengan prestasi siswa pada mata pelajaran Materi matriks, dimana mata pelajaran tersebut terdapat pada SMA Negeri 1 Comal Tahun Pelajaran 2021/2022.

Penelitian ini memiliki Rumusan Masalah yaitu Bagaimana pelaksanaan pembelajaran untuk memfasilitasi tingkat prestasi mahasiswa siswa pada tingkat menengah, dan meningkatkan motivasi belajar dengan lingkungan yang nyaman dan menyenangkan. Dan Tujuan dari penelitian ini adalah untuk melihat seberapa efektivitas pembelajaran dengan jenis Pembelajaran yang Aktif, Kreatif dan Menyenangkan sehingga proses pembelajaran matematika pada materi Matriks, sehingga hasil prestasi matematika dapat meningkat.

\section{METODE PENELITIAN}

\section{Desain Penelitian}

Pada penelitian ini memiliki desain sebagai berikut : 


\begin{tabular}{|c|c|c|}
\hline Kelompok & Perlakuan & Test \\
\hline $\mathrm{A}$ & $\mathrm{x}_{1}$ & $\mathrm{y}_{1}$ \\
\hline $\mathrm{B}$ & $\mathrm{x}_{2}$ & $\mathrm{y}_{2}$ \\
\hline
\end{tabular}

keterangan :

$\mathrm{x} 1$ = Mengajar dengan PAKEM

$\mathrm{x} 2$ = Mengajar dengan tanpa PAKEM

y1 = Hasil mata pelajaran Materi matriks kelompok A

y2 = Hasil mata pelajaran Materi matriks kelompok B

Namun kedua kelompok diberi materi yang sama yaitu mata pelajaran Materi matriks, dengan jumlah waktu yang sama, dan guru yang sama. Selanjutnya hasil belajar dari kedua kelompok dibandingkan apakah sama atau ada perbedaan.

\section{Variabel Penelitian}

Variabel pada penelitian ini dapat berdasarkan tujuan penelitian sebagai berikut :

$\mathrm{x} 1$ = Pembelajaran dengan PAKEM pada kelompok A

$\mathrm{x} 2=$ Pembelajaran dengan tanpa PAKEM pada kelompok B

Sedangkan variabel responnya adalah hasil belajar mata pelajaran Materi matriks, pada kelompok A (y1) dan kelompok B (y2). Dengan Deskripsi gambar seperti ilustrasi dibawah ini.

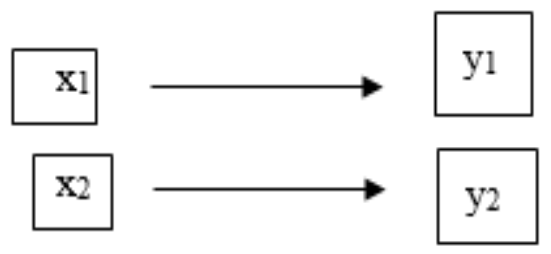

Keterangan :

x1: $\quad$ Pembelajaran mata pelajaran Materi matriks dengan PAKEM

x2: $\quad$ Pembelajaran mata pelajaran Materi matriks tanpa PAKEM

y1: Hasil mata pelajaran Materi matriks kelompok A

y2: Hasil mata pelajaran Materi matriks kelompok B

\section{Metode Pengumpulan Data}

Pada penelitian ini memiliki beberapa pengumpulan data diantaranya sebagai berikut :

a. Metode Dokumentasi

Yaitu dengan cara mencari data untuk memperoleh daftar nama siswa yang nantinya akan digunakan sebagai sampel penelitian. Kemudian pengumpulannya menggunakan tenik dokumentasi yang merupakan teknik mengumpulkan data dengan cara menggunakan dokumentasi, dokumen rapat, hasil tes, daftar nilai, dll.

Jenis teknik dokumentasi yang digunakan adalah teknik dokumentasi dari rata-rata nilai awal siswa, seperti nilai sebelumnya dan nilai ujian tengah semester. Cara pelaksanaan pada proses dokumentasi memiliki langkah-langkah sebagai berikut :

a) Mendata Identitas peserta penelitian yang merupakan bagian dari penelitian

b) Mendata Prestasi/Hasil Belajar Siswa

b. Metode Tes

Metode Tes yang digunakan merupakan serangkaian pertanyaan atau latihan yang mengukur kemampuan keterampilan dan bakat yang dimiliki oleh individu atau kelompok

Sebuah Tes dapat memiliki predikat valid apabila mampu menilai yang di inginkan/memperoleh data sesuai tujuan penelitian. Indikator variabel menggunakan soal tes, soal tes yang disusun tersebut haruslah dapat mengukur mengenai pemahaman diri dan perilaku 
belajar, dengan sampel uji coba siswa yang berasal dari siswa SMA Negeri Comal Tahun Pelajaran 2021/2022.

Langkah selanjutnya adalah melihat nilai Reliabilitas yang merupakan indeks untuk mengetahui/mengukur kepercayaan suatu nilai.

\section{Analisis Data Awal}

a. Uji Normalitas

b. Uji Homogenitas

c. Uji t

Uji t memiliki tujuan untuk mengetahui uji hipotesis/akhir penelitian, apakah $\mathrm{H}_{0}$ diterima atau ditolak. Dengan ketentuan kedua kelompok homogen, dan dapat digunakan formula rumus sebagi berikut :

$$
\begin{aligned}
\mathrm{t} & =\frac{\overline{X_{1}}-\overline{X_{2}}}{S \sqrt{\frac{1}{n_{1}}+\frac{1}{n_{2}}}} \\
\mathrm{~S}^{2} & =\frac{\left(n_{1}-1\right) S_{1}{ }^{2}+\left(n_{2}-1\right) S_{2}{ }^{2}}{\left(n_{1}-1\right)+\left(n_{2}-1\right)}
\end{aligned}
$$

Ket :

n1 : Banyaknya subyek kelompok ekpserimen

n2 : Banyaknya subyek kelompok kontrol

$\overline{X_{1}} \quad$ : Nilai rerata Kelas/kelompok eksperimen

$X_{2} \quad$ : Nilai rerata Kelas/kelompok kontrol

$\mathrm{S}_{1}^{2} \quad$ : Varians kelompok eksperimen

$\mathrm{S}_{2}{ }^{2} \quad$ : Varians kelompok control

\section{HASIL DAN PEMBAHASAN}

\section{a. Hasil}

Pada penelitian ini, mulai dari persiapan, pelaksanaan penelitian, pengumpulan data, analisis dan pembahsasan hasil penelitian. Pada pembahasan persiapan penelitian akan dibahas penentuan subyek penelitian dan pembuatan soal tes. Pada pelaksanaan penelitian akan dibahas tentang pemberian materi dan pelaskanaan tes. Pada pembahasan mengenai pengumpulan data diungkapkan hal-hal mengenai hasil daya pembeda, validitas dan reliabilitas soal dan tingkat kesulitan.

Hasil mengenai analisis data diungkapkan mengenai uji prasyarat yang meliputi normalitas, homogenitas dan uji hipotesis. Adapun pembahasan hasil penelitian meliputi Pemberian Materi dan Pelaksanaan Uji Coba.

Kemudian pada perhitungan reliabilitas soal dengan hasil yang di dapat kemudian dibandingkan dengan $r$ tabel dengan $\mathrm{N}=40$ taraf 5\% ternyata sebesar 0,312, maka hasilnya $0,8876>0,31$ atau $r$ hitung $>r$ tabel. Sehingga dapat disimpulkan bahwa instrumen uji coba yang disusun mempunyai tingkat reliabilitas tinggi dan telah memenuhi syarat sebagai pengumpul data.

\section{Analisis Uji T}

Dari hasil perhitungan yang menggunakan uji t berikut :

$$
t=\frac{\bar{X}_{1}-\bar{X}_{2}}{S \sqrt{\frac{1}{n_{1}}+\frac{1}{n_{2}}}}
$$


dengan,

$$
S^{2}=\frac{\left(n_{1}-1\right) S_{1}^{2}+\left(n_{2}-1\right) S_{2}^{2}}{n_{1}+n_{2}-2}
$$

$$
t=\frac{\bar{X}_{1}-\bar{X}_{2}}{S \sqrt{\frac{1}{n_{1}}+\frac{1}{n_{2}}}}
$$

dengan,

$$
S^{2}=\frac{\left(n_{1}-1\right) S_{1}^{2}+\left(n_{2}-1\right) S_{2}^{2}}{n_{1}+n_{2}-2}
$$

dengan diketahui :

$$
\begin{aligned}
& \bar{X}_{1}=64,08 \quad \bar{X}_{2}=63,25 \\
& \mathrm{~S}_{1}{ }^{2}=80,76 \quad \mathrm{~S}_{2}{ }^{2}=90,6875 \\
& \mathrm{n}_{1}=38 \quad 40 \\
& S^{2}=84,882 \\
& S=9,213 \\
& t=\frac{\bar{X}_{1}-\bar{X}_{2}}{S \sqrt{\frac{1}{n_{1}}+\frac{1}{n_{2}}}} \\
& t=\frac{64,09-63,25}{9,213 \sqrt{\frac{1}{38}+\frac{1}{40}}} \\
& t=\frac{0,84}{9,213 \sqrt{0,0513}} \\
& t=\frac{0,84}{9,213 \times 0,2265} \\
& t=0,403
\end{aligned}
$$

Diperoleh nilai $t_{\text {hitung }}$ adalah 0,40 kemudian nilai $t_{\text {tabel }}$ dengan batas peluang peluang $(1-1 / 2 \alpha)$ pada derajat kebebasan $=\left(n_{1}+n_{2}-2\right)=76, \alpha=0,05$ adalah sebesar 1,98. Karena $t_{\text {hitung }} \leq t$ tabel , sehingga dapat disimpulkan bahwa kedua kelas/kelompk tidak memiliki perbedaan rerata secara secara signifikan. Pengujian Uji t memiliki tujuan mengetahui hasil akhir penelitian, apakah pada penelitian $\mathrm{H}_{0}$ ditolak atau diterima. Selanjutnya, karena dua kelas/kelompok tersebut merupakan kelompok ketika dibandingkan adalah kelompok yang tidak homogen, maka uji t menggunakan rumus sebagai berikut :

$$
t=\frac{\bar{X}_{1}-\bar{X}_{2}}{S \sqrt{\frac{1}{n_{1}}+\frac{1}{n_{2}}}}
$$

Hipotesis/Dugaan pada penelitian ini adalah sebagai berikut :

$\mathrm{H}_{0}=$ Memiliki arti bahwa Tidak ada pengaruh prestasi siswa mata pelajaran Materi matriks pada siswa yang melalui proses pembelajaran yang diajar dengan metode PAKEM lebih baik dari siswa tanpa proses pembelajaran PAKEM 
$\mathrm{H}_{\mathrm{a}}=$ Memiliki arti bahwa ada pengaruh prestasi siswa mata pelajaran Materi matriks pada siswa yang melalui proses pembelajaran yang diajar dengan metode PAKEM lebih baik dari siswa tanpa proses pembelajaran PAKEM

Batas nilai pengujian ketika $\mathrm{H}_{0}$ ditolak adalah sebagai berikut :

$t_{\text {hitung }}>t_{\text {tabel }}$

Berdasarkan pada lampiran diperoleh nilai-nilai sebagai berikut:

$\bar{X}_{1}=76,84$

$\bar{X}_{2}=61,75$

$\mathrm{S}_{1}^{2}=104,50$

$\mathrm{S}_{2}{ }^{2}=124,44$

$\mathrm{n}_{1}=38 \mathrm{n}_{2}=40$

$t=\frac{76,84-61,75}{10,711 \sqrt{\frac{1}{38}+\frac{1}{40}}}$

$t=\frac{15,09}{10,711 \sqrt{0,0513}}$

$t=\frac{15,09}{10,711 \times 0,2265}$

$t=6,220$

\section{b. Pembahasan}

Dari perhitungan di atas nilai $\mathrm{t}=2,68$ sedangkan nilai $\mathrm{t}$ hitung $=6,220$ dengan hasil tersebut diperoleh hitung $>\mathrm{t}$ tabel, dengan demikian $\mathrm{H}_{0}$ ditolak sehingga $\mathrm{H}_{\mathrm{a}}$ diterima dan dapat disimpulkan bahwa prestasi/hasil belajar siswa yang melalui proses pembelajaran dengan PAKEM lebih baik daripada siswa yang tidak melalui proses pembelajaran dengan PAKEM, atau dengan istilah lain bahwa peningkatan prestasi/hasil belajar pada kelompok eksperimen jauh lebih baik dari pada kelompok kontrol.

Hasil uji t yang telah dihitung memperoleh hasil $t_{\text {hitung }}=6,220$, maka $t_{\text {hitung }}>t_{\text {tabel }}$ artinya Ha diterima bahwa ada pengaruh prestasi siswa mata pelajaran Materi matriks pada siswa yang melalui proses pembelajaran dengan PAKEM lebih baik daripada siswa yang tidak melalui proses pembelajaran dengan PAKEM.

Hal ini menunjukkan bahwa ada perbedaan yang cukup berarti mengenai hasil belajar siswa yang melalui proses pembelajaran dengan PAKEM (Wardani, 2015). Adapun hal terkait dengan penggunaan metode pembelajaran PAKEM adalah sebegai berikut :

1. Siswa yang bersama dalam proses pembelajaran ini dapat mengembangkan kemampuankemampuannya seperti keterampilan dan pemahamannya.

2. Penggunaan berbagai stimulus / motivasi dimaksudnya agar proses pembelajaran lebih efektif dan semakin dekat dengan tujuan pembelajaran yaitu meningkatkan prestasi belajar dan membuat situasi pembelajaran yang kondunsif dan menyenangkan.

3. Guru akan semakin termotivasi mendorong siswa agar dapat semakin terampil dalam menyelesaiakan masalahnya, mengungkapkan ide/gagasan sehingga tercipta kondisi lingkungan pembelajaran yang efektif.

\section{KESIMPULAN}

Berdasarkan hasil penelitian dan analisis secara statistik terhadap data yang diperoleh hasil tes kelompok eksperimen sebesar 76,84 sedangkan pada kelompok kontrol sebesar 61,75 setelah dilakukan perhitungan diperoleh $t_{\text {hitung }}=6,22$ sedangkan $t_{\text {tabel }}=2,68$ kemudian dari dua data tersebut ketika dibandingakan maka $t_{\text {hitung }}>t_{\text {tabel }}$ dari perbandingan tersebut 
dapat diartikan bahwa ada pengaruh yang positif pada kemampuan/hasil belajar pada siswa yang melalui proses belajar dengan Metode PAKEM sehingga di peroleh kesimpulan : (a) Dengan melihat hasil prestasi siswa dapat pula disimpulkan bahwa kemampuan/hasil prestasi siswa yang melalui proses pemebelajaran PAKEM lebih baik dari kelompok siswa yang tidak melalui proses pembelajaran dengan PAKEM, (b) Siswa yang bersama dalam proses pembelajaran ini dapat mengembangkan kemampuan-kemampuannya seperti keterampilan dan pemahamannya, (c) Penggunaan berbagai stimulus / motivasi dimaksudnya agar proses pembelajaran lebih efektif dan semakin dekat dengan tujuan pembelajaran yaitu meningkatkan prestasi belajar dan membuat situasi pembelajaran yang kondunsif dan menyenangkan, (d)Guru akan semakin termotivasi mendorong siswa agar dapat semakin terampil dalam menyelesaiakan masalahnya, mengungkapkan ide/gagasan sehingga tercipta kondisi lingkungan pembelajaran yang efektif.

\section{DAFTAR PUSTAKA}

Murdiyanto, E. K. O. (2011). Partisipasi masyarakat dalam pengembangan desa wisata karanggeneng, purwobinangun, pakem, sleman. 7(2), 91-101.

Mustafa, P. S. (n.d.). Penerapan Teori Belajar Konstruktivisme melalui Model PAKEM dalam Permainan Bolavoli pada Sekolah Menengah Pertama. 6(1), 50-65.

Nym, N., Pradnyawathi, C., Ngr, G., \& Agustika, S. (2019). Pengaruh Model Pakem Berbasis Tri Hita Karana terhadap Keterampilan Menulis. 3(1), 89-98.

LESTARI, L. (2014). Efektivitas Pelaksanaan Pakem Pada Pembelajaran PKn di SD Negeri 1 Wonosari Kecamatan Wonosari Kabupaten Boalemo. Skripsi, 1(221410243).

Qurohman, M. T., \& Sungkar, M. S. (2018). Integrasi Pembelajaran Matematika Problem Based Learning dengan Teknologi Informasi dan Komunikasi. Desimal: Jurnal Matematika, 1(3), 303-313. https://doi.org/10.24042/djm.v1i3.2908

Qurohman, M. T., Sungkar, M. S., \& Abidin, T. (2020). Improvement of Students' Ability With Mathematics Learning Innovation Based on Handphone Technology. 467(Semantik 2019), 50-55. https://doi.org/10.2991/assehr.k.200827.116

Qurohman, M. T., Sungkar, M. S., Abidin, T., \& Polytechnic, H. B. (2019). Development of Mathematics Learning Application Based on. 06(02).

Sekolah, D. I. (2009). IMPLEMENTASI PEMBELAJARAN AKTIF KREATIF EFEKTIF DAN MENYENANGKAN ( PAKEM ) UNTUK PENDIDIKAN SAINS. 3(2), 19-28.

Wardani, N. S. (2015). Implementasi Pakem Melalui Model Pembelajaran Aktif Dalam Perkuliahan Konsep Dasar IPS SD Berbasis Pendidikan Kecakapan Hidup. Prosiding Ilmu Pendidikan, 1(2).

Teologi, J., Kristen, A., \& Sidabutar, J. L. (2020). Pengaruh Model Pakem terhadap Hasil Belajar Siswa Pendidikan Agama Kristen. 2(1), 15-31. 